\title{
Outcome of the 'Drip-and-Ship' Paradigm among Patients with Acute Ischemic Stroke: Results of a Statewide Study
}

\author{
Adnan I. Qureshi Saqib A. Chaudhry Gustavo J. Rodriguez \\ M. Fareed K. Suri Kamakshi Lakshminarayan \\ Mustapha A. Ezzeddine \\ Departments of Neurology, Zeenat Qureshi Stroke Research Center, University of Minnesota, \\ and Hennepin County Medical Center, Minneapolis, Minn., USA
}

\section{Key Words}

Acute stroke - Drip-and-ship paradigm • Emergency department $\cdot$ Ischemic stroke •

Recombinant tissue plasminogen activator $\cdot$ Thrombolysis $\cdot$ Triage

\begin{abstract}
Background: The 'drip-and-ship' paradigm denotes a treatment regimen in patients in whom intravenous (IV) recombinant tissue plasminogen activator (rt-PA) is initiated at the emergency department (ED) of a community hospital, followed by transfer within $24 \mathrm{~h}$ to a comprehensive stroke center. Although the drip-and-ship paradigm has the potential to increase the number of patients who receive IV rt-PA, comparative outcomes have not been assessed at a population-based level. Methods: Statewide estimates of thrombolysis, associated in-hospital outcomes, and hospitalization charges were obtained from 2008-2009 Minnesota Hospital Association data for all patients hospitalized with a primary diagnosis of ischemic stroke. Patients who were assigned the drip-and-ship code [International Classification of Diseases, 9th revision, Clinical Modification (ICD-9-CM) V45.88] were classified under the drip-and-ship paradigm. Patients who underwent thrombolysis (ICD-9-CM code 99.10) without drip-and-ship code were classified as primary ED arrival. Patient outcomes were analyzed after stratification into patients treated with IV rt-PA through primary ED arrival or drip-and-ship paradigm. Results: Of the 21,024 admissions, $602(2.86 \%)$ received IV rt-PA either through primary ED arrival $(n=473)$ or the drip-and-ship paradigm $(n=129)$. IV rt-PA was administered in 30 hospitals, of which 13 hospitals used the drip-and-ship paradigm; the number of patients treated with the drip-and-ship
\end{abstract}




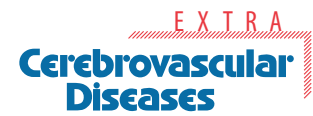

Diseases

\begin{tabular}{l|l}
\hline Cerebrovasc Dis Extra 2012;2:1-8 \\
\hline DOl: 10.1159/000335097 & $\begin{array}{l}\text { @ 2012 S. Karger AG, Basel } \\
\text { www.karger.com/cee }\end{array}$ \\
\hline Published online: January 10, 2012 &
\end{tabular}

Qureshi et al.: rt-PA: Drip-and-Ship Paradigm

paradigm varied from 1 to 40 between the 13 hospitals. The rates of secondary intracerebral or subarachnoid hemorrhage were higher in patients treated with IV rt-PA through primary ED arrival compared with those treated with the drip-and-ship paradigm ( $8.5 \mathrm{vs.} 3.1 \%$, respectively; $p=0.038$ ). The in-hospital mortality rate was similar among ischemic stroke patients receiving IV rt-PA through primary ED arrival or the drip-and-ship paradigm (5.9 vs. $7.0 \%$, respectively). The mean hospital charges were USD 65,669 for primary ED arrival and USD 47,850 for drip-andship-treated patients $(p<0.001)$. The rate of admission to a certified stroke center as final destination for acute hospitalization was higher in patients treated by drip-and-ship paradigm compared with those treated by primary ED arrival mode $(p=0.015)$. Conclusions: The results of the drip-and-ship paradigm compare favorably with IV rt-PA treatment through primary ED arrival in this statewide study. Our results support the recommendations of various professional organizations that the drip-and-ship method of IV rt-PA administration for stroke may be an effective option for increasing the utilization of IV rt-PA on a large scale.

Copyright $\odot 2012$ S. Karger AG, Basel

\section{Introduction}

Since the publication of the results of the NINDS recombinant tissue plasminogen activator (rt-PA) Stroke Trial in December 1995 [1] and US Food and Drug Administration approval in June 1996, a substantial effort has been undertaken at both the national and regional level to increase the proportion of patients with ischemic stroke who receive thrombolysis, including a relatively new 'drip-and-ship' strategy. 'Drip and ship' is a term used to identify patients in whom intravenous (IV) rt-PA is initiated at the emergency department (ED) of a community hospital, followed by transfer within $24 \mathrm{~h}$ to a comprehensive stroke center. A new International Classification of Diseases, 9th revision, Clinical Modification (ICD-9-CM), diagnosis code V45.88, was approved by the Centers for Medicare and Medicaid Services on October 1, 2008, to identify patients treated by the 'drip-and-ship' paradigm. Several studies have reported single center experiences with the drip-and-ship paradigm and provided comparative outcomes with patients treated at primary ED arrival [2-4]. However, no population-based study has evaluated the results of this paradigm in general practice.

There are reasons to believe that the results of 'drip-and-ship' treatment may not be as promising as reported in single center studies. Single centers may have a well-developed relationship with referring EDs with protocol sharing and real-time assistance through telephone or video conferencing [5]. There is also a sampling bias influenced by the population served by the study center which may yield different results due to variations in acute interventions within population groups [6]. A population-based study is more likely to reflect the heterogeneity of implementation by various practices and the study sample is more reflective of various racial/ethnic and socioeconomic population groups.

\section{Methods}

The population of the state of Minnesota $\left(225,171 \mathrm{~km}^{2}\right)$ in 2009 according to the census was 5,266,214 persons. Whites and African Americans form 87 and 5\% of the population, respectively; $4 \%$ were categorized as persons of Hispanic or Latino origin [7]. Thirteen percent of the population is aged $\geq 65$ years and $50 \%$ of the overall population is female.

The Minnesota Hospital Association (MHA) is a trade association representing 148 hospitals in Minnesota. Under agreement with the Minnesota Department of Health, MHA 
serves as the voluntary, nonprofit reporting organization for the collection of the Health Care Cost Information System hospital-specific financial, utilization, staffing and service data. The data are required by Minnesota Statutes Section 144.695-144.703 and Minnesota Rules, chapter 4650, and are a database of key hospital indicators maintained for comparative reporting. There are $>500$ data elements in the database [8]. Since 1993, the data are based on the Uniform Bill, 1992 version (UB-92). The MHA database is de-identified, which is an exemption for institutional review board review. In 1995, the database was expanded to invite all Minnesota acute care hospitals to submit data on both in- and outpatient claims on a voluntary basis. All standard administrative data elements were collected, including admission and discharge dates, admission source, discharge type, age, sex, ICD-9-CM diagnosis codes with present-on-admission modifiers and ICD-9-CM procedure codes with date procedures performed.

We analyzed the MHA public use data files from October 2008 to December 2009. We used the ICD-9-CM [9] as primary or secondary diagnosis codes to identify the patients admitted with ischemic stroke. Diagnostic code fields were screened for specific codes to identify patients with ischemic stroke using ICD-9 codes $433,434,436,437.0$, and 437.1 as primary or secondary discharge diagnoses. Patients who were assigned the drip-and-ship code (ICD-9-CM V45.88 code) were classified as receiving treatment using the drip-and-ship paradigm. Patients receiving thrombolysis (identified by ICD-9-CM procedure code 99.10) without drip-and-ship code were classified as primary ED arrival. If thrombolysis was administered to patients with ICD-9-CM secondary diagnosis codes to identify those with stroke-associated complications such as pneumonia $(481,482.3,482.8$, or 486$)$, urinary tract infection (590.9 or 599.0), sepsis $(038,995.91,995.92,996.64$, or 999.3), deep venous thrombosis (451.1, 451.2, 451.81, 451.9, 453.1, 453.2, 453.8, or 453.9), pulmonary embolism (415.1), intracerebral $(\mathrm{ICH})$ or subarachnoid hemorrhage $(430,431$, or 432$)$, and acute myocardial infarction (410). We also used ICD-9-CM procedure codes to estimate the percentage of stroke patients who underwent stroke-related procedures such as cerebral angiography (88.41), carotid angioplasty/stent placement (00.63/00.64), intracranial angioplasty/stent placement (00.62/00.65), gastrostomy (43.11-43.19), tracheostomy $(31.10,31.20,31.21$, or 31.29), and carotid endarterectomy (38.12). We also determined the rate of admission to a certified stroke center (14 centers are certified by the Joint Commission in Minnesota) as final destination of acute hospitalization in both groups.

We also ascertained the following variables between the two groups: age, sex, length of hospitalization, discharge status [categorized into home (routine), home health care, shortterm hospital, other long-term facilities including intermediate care and skilled nursing home, or death], and medical complications: procedures performed and total cost of hospitalization. We used the $\chi^{2}$ test for categorical data and analysis of variance for continuous data to detect any significant differences in variables among patients treated with IV rt-PA either as primary ED arrival mode or using the drip-and-ship paradigm.

\section{Results}

There were 21,024 admissions for ischemic stroke in Minnesota-based hospitals. Of these admissions, 602 (2.86\%) underwent treatment with IV rt-PA. Of these 602 patients, 473 received thrombolysis through primary ED arrival and 129 received thrombolysis through the drip-and-ship paradigm. IV rt-PA was administered in 30 hospitals and 13 of them used the drip-and-ship paradigm; the number of patients treated with the drip-and-ship paradigm varied from 1 to 40 between the 13 hospitals. More than half of the patients treated with the drip-and-ship paradigm were admitted to 2 hospitals (37 and 40 patients). The rate 


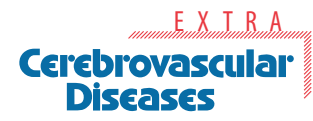

\begin{tabular}{l}
\hline \begin{tabular}{l}
\hline Cerebrovasc Dis Extra 2012;2:1-8 \\
\hline DOI: 10.1159/000335097
\end{tabular} \\
$\begin{array}{l}\text { Published online: January 10, 2012 } 2012 \text { Karger AG, Basel } \\
\text { www.karger.com/cee }\end{array}$ \\
\hline
\end{tabular}

Qureshi et al.: rt-PA: Drip-and-Ship Paradigm

Table 1. Demographic and clinical characteristics of the patients treated with thrombolysis through primary ED arrival or the drip-and-ship paradigm (MHA data: October 2008 to December 2009)

\begin{tabular}{|c|c|c|c|}
\hline & Primary ED arrival & Drip-and-ship paradigm & $\mathrm{p}$ value \\
\hline Patients, n & 473 & 129 & \\
\hline Women & $226(47.8 \%)$ & $60(46.5 \%)$ & 0.798 \\
\hline Mean age $\pm S D$, years & $69.72 \pm 15.9$ & $71.69 \pm 13.6$ & 0.201 \\
\hline \multicolumn{4}{|l|}{ Final destination for acute hospitalization } \\
\hline Uncertified center & $66(13.9 \%)$ & $8(6.2 \%)$ & \multirow[t]{2}{*}{0.015} \\
\hline Certified stroke center ${ }^{1}$ & $407(86.1 \%)$ & $121(93.8 \%)$ & \\
\hline \multicolumn{4}{|l|}{ Medical complications } \\
\hline Subarachnoid hemorrhage/ICH & $40(8.5 \%)$ & $4(3.1 \%)$ & 0.038 \\
\hline Myocardial infarction & $18(3.8 \%)$ & $1(0.8 \%)$ & 0.092 \\
\hline Pneumonia & $25(5.3 \%)$ & $3(2.3 \%)$ & 0.236 \\
\hline Urinary tract infection & $51(10.8 \%)$ & $14(10.9 \%)$ & 0.982 \\
\hline Sepsis & $10(2.1 \%)$ & $0(0 \%)$ & 0.130 \\
\hline Pulmonary embolism & $7(1.5 \%)$ & $1(0.8 \%)$ & 1.000 \\
\hline Deep venous thrombosis & $3(0.6 \%)$ & $1(0.8 \%)$ & 1.000 \\
\hline \multicolumn{4}{|l|}{ Procedures } \\
\hline Cerebral angiography & $137(29 \%)$ & $41(31.8 \%)$ & 0.534 \\
\hline Mechanical ventilation & $11(2.3 \%)$ & $1(0.8 \%)$ & 0.234 \\
\hline Gastrostomy & $20(4.2 \%)$ & $9(7.0 \%)$ & 0.196 \\
\hline Tracheostomy & $4(0.8 \%)$ & $1(0.8 \%)$ & 1.000 \\
\hline Carotid angioplasty/stent placement & $11(2.3 \%)$ & $2(2.6 \%)$ & 0.591 \\
\hline Intracranial angioplasty/stent placement & $8(1.7 \%)$ & $3(2.3 \%)$ & 0.634 \\
\hline \multicolumn{4}{|c|}{$\begin{array}{l}\text { None of the patients was treated with carotid endarterectomy. SD = Standard deviation; ICA = intra- } \\
\text { cerebral hemorrhage. } \\
{ }^{1} \text { Certified by the Joint Commission. }\end{array}$} \\
\hline
\end{tabular}

of admission to a certified stroke center as final destination for acute hospitalization was higher in patients treated with the drip-and-ship paradigm compared with those treated by primary ED arrival mode $(\mathrm{p}=0.015)$. Table 1 demonstrates the demographic and clinical characteristics of the patients according to the treatment used. The mean age was similar between the two groups. The rates of medical complications appeared to be similar between the two patient groups. The rates of additional procedures including cerebral angiography, mechanical ventilation, gastrostomy, and carotid or intracranial stent placement were similar between the two patient groups.

The mean length of hospitalization $( \pm \mathrm{SD})$ was $5.98( \pm 4.8)$ versus $5.11( \pm 3.7)$ days among patients treated with IV rt-PA through primary ED arrival or the drip-and-ship paradigm, respectively (table 2). The rates of secondary ICH or subarachnoid hemorrhage were higher in patients treated with IV rt-PA through primary ED arrival compared with those treated with the drip-and-ship paradigm ( 8.5 vs. 3.1, respectively; $\mathrm{p}=0.038$ ). The in-hospital mortality rate was similar among ischemic stroke patients receiving IV rt-PA through primary ED arrival or through the drip-and-ship paradigm (5.9 vs. 7.0\%, respectively). The rate of discharge to home following hospitalizations was similar between patients receiving IV rt-PA through primary ED arrival or the drip-and-ship paradigm (31.9 vs. 34.9\%, respectively). The mean hospital charges were USD 65,669 for primary ED arrival and USD 47,850 for the drip-and-ship-treated patients $(\mathrm{p}<0.001)$. 


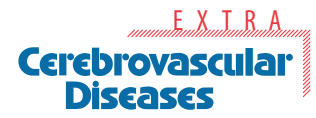

\begin{tabular}{|c|c|}
\hline Cerebrovasc Dis Extra 2012;2:1-8 & \\
\hline $\begin{array}{l}\text { DOI: 10.1159/000335097 } \\
\text { Published online: January 10, } 2012\end{array}$ & $\begin{array}{l}\text { (c) } 2012 \text { S. Karger AG, Basel } \\
\text { www.karger.com/cee }\end{array}$ \\
\hline
\end{tabular}

Table 2. In-hospital outcomes of the patients treated with thrombolysis through primary ED or the dripand-ship paradigm (MHA data: October 2008 to December 2009)

\begin{tabular}{lccc}
\hline & Primary ED arrival & Drip-and-ship paradigm & p value \\
\hline Patients, $n$ & 473 & 129 & \\
Home (routine) & $151(31.9 \%)$ & $45(34.9 \%)$ & 0.525 \\
Home health care & $26(5.5 \%)$ & $4(3.1 \%)$ & 0.363 \\
Short-term hospital & $117(24.7 \%)$ & $32(24.8 \%)$ & 0.987 \\
Long-term facilities & $150(31.7 \%)$ & $39(30.2 \%)$ & 0.787 \\
In-hospital mortality & $28(5.9 \%)$ & $9(7.0 \%)$ & 0.658 \\
Not stated/missing & $1(0.2 \%)$ & $0(0 \%)$ & 0.601 \\
Hospitalization & & $5.11 \pm 3.7$ & 0.872 \\
Mean length \pm SD, days & $5.98 \pm 4.8$ & 47,850 & $<0.001$ \\
Charges, USD & 65,669 & & \\
\hline
\end{tabular}

\section{Discussion}

In this statewide data set, we found similar outcomes for patients treated with intravenous thrombolysis either after primary ED arrival or through the drip-and-ship paradigm, in agreement with results derived from single center studies [2-4]. Of these 602 patients who received IV rt-PA in Minnesota, 473 and 129 patients were treated through primary ED arrival and the drip-and-ship paradigm. A proportion of the 129 patients who received IV rtPA through the drip-and-ship paradigm may not have received IV rt-PA without availability of this treatment method. The proportion of these patients would be higher in states where the Emergency Medical Services transport patients to the nearest available ED in the absence of preexisting designated hospital EDs for acute stroke patients. In addition, patients treated with the drip-and-ship paradigm were more likely to be admitted to a certified stroke center as the final destination for acute hospitalization. The strategy appeared to be costeffective in our analysis, but the hospital charges are confounded by the fact that IV rt-PA was administered at the originating hospital but the patient is admitted to the receiving hospital. DRG 559 cannot be utilized by the receiving hospital because no thrombolytic agent was administered at the receiving hospital. Thus the hospital charges may not account for added costs associated with the initial care of patients receiving the thrombolytic agent.

The comparable outcomes seen in patients treated with the drip-and-ship paradigm in our study are presumably attributable to the ability of ED physicians to identify stroke patients who are candidates for IV rt-PA with or without expedient consultation with the stroke team of the receiving hospital. One study [10] compared assessment of eligibility for IV rt-PA by ED physician and stroke neurology physician in a sample of patients presenting with possible stroke symptoms. Agreement with the stroke neurologist for IV rt-PA eligibility was 93\% when compared with the ED physician. In another study [4], the accuracy of ischemic stroke diagnosis (by radiographic confirmation) was similar between patients receiving IV rt-PA through primary ED arrival or the drip-and-ship paradigm. Rapid acquisition of CT scan images at referring EDs and remote expert interpretation have also favorably impacted the drip-and-ship paradigm [11]. Many referral hospitals initiate IV rt-PA using telemedicine or telephone consultation before transferring patients to a regional stroke center and, therefore, acquire guidance from stroke specialists in a time-efficient manner. In an analysis of selected data from the Get-with-the-Guidelines initiative [5], 13 of the 33 referral hospitals had an established telemedicine connection with the hospital during the study period; the remainder used the telephone. Among the 181 drip-and-ship cases in the study, supervision 


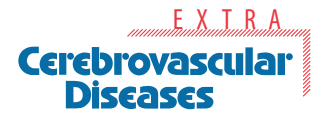

\begin{tabular}{l|l}
\hline Cerebrovasc Dis Extra 2012;2:1-8 \\
\hline $\begin{array}{l}\text { DOI: } 10.1159 / 000335097 \\
\text { Published online: January 10, 2012 }\end{array}$ & $\begin{array}{l}\text { @ 2012 S. Karger AG, Basel } \\
\text { www.karger.com/cee }\end{array}$ \\
\hline
\end{tabular}

Qureshi et al.: rt-PA: Drip-and-Ship Paradigm

of thrombolysis was by telestroke in 84 (46.4\%) and telephone in 97 (53.6\%) patients. Televideo consultation increased the accuracy of decision and rate of rt-PA administration in 1 randomized trial [12].

Our study supports the recommendations of various professional organizations that the drip-and-ship paradigm of rt-PA administration for stroke may be an effective option for increasing the utilization of IV rt-PA in the United States. The American Stroke Association's Task Force on the Development of Stroke Systems [13] recommended that 'a stroke system must develop strategies that incorporate hospitals that do not intend to seek stroke center status. All hospitals and facilities that could be involved in the care of acute stroke patients should develop action plans for the triage and treatment (or transport) of stroke patients'. The drip-and-ship paradigm is consistent with the goal of the task forces to ensure that suspected stroke patients should receive timely acute primary stroke care at any hospital in the stroke system according to a prespecified care plan. The extensive area that can be covered through the drip-and-ship paradigm is highlighted by analyses of the regional hospital stroke referral network surrounding Saint Luke's Hospital Stroke Center in Kansas City [2] and of the University of Texas-Houston Health Science Center [4]. These studies found that the referring hospitals participating in the drip-and-ship paradigm can range in distance from 160 to $650 \mathrm{~km}$ from the receiving hospital.

The accuracy of our analysis depended upon the accuracy of ICD-9-CM codes V45.88 and 99.10 on UB-92 summaries. In anticipation of such studies, we had recently studied the accuracy of the new V45.88 code for identifying ischemic stroke patients who meet the criteria for the drip-and-ship paradigm at 2 of the participating hospitals in Minnesota [14]. Out of a total of 428 patients discharged from both hospitals with a diagnosis of ischemic stroke, 37 patients were given ICD-9-CM code V45.88. The internally validated data from the prospective stroke database maintained at these 2 hospitals demonstrated that a total of 40 patients met the criteria for the drip-and-ship paradigm. A concurrent comparison found that $92 \%$ (sensitivity) of the patients treated with the drip-and-ship paradigm were coded with V45.88. None of the non-drip-and-ship stroke cases received the V45.88 code (100\% specificity). The positive predictive value of V45.88 was $100 \%$. Previously, we had also studied [15] the accuracy of ICD-9 procedure code 99.10 for use of thrombolysis in ischemic stroke by comparing procedure codes of University Hospital discharge data with a concurrent prospective registry. The procedure code 99.10 was designated for injection or infusion of thrombolytic agents permitting estimation of national and statewide use in 1998 [16]. The sensitivity and specificity for ICD-9 procedure code 99.10 in our study was 55 and 98\%, respectively. The high specificity of both codes suggests that the patient designation for each category is most likely accurate, although the exact prevalence may be underestimated $[14,15,17]$.

We used the data from the MHA, a large data set designed to be representative of the Minnesota state population. One disadvantage of the MHA database is that it provides minimal clinical details on the severity of patients' neurological deficits, on diagnostic study results, or on patients' medications. We also acknowledge the limitations with case ascertainment using such methodology $[14,15,17]$. To avoid missing any patients who underwent thrombolysis, we included all patients with ICD-9-CM codes for ischemic stroke either as primary or secondary discharge diagnoses. A previous study [18] indicated that studies which use primary and secondary ICD-9-CM discharge codes to measure stroke occurrence will overestimate the number of hospitalized strokes in the population. The overestimation of the denominator for the derivation of $2.9 \%$ rt-PA utilization rate is likely to underestimate the actual rate of utilization. The denominator did not adjust for the time interval between symptom onset and admission (including a large proportion of non-candidates), in-hospital strokes, or multiple admissions of the same patient, which further confound the estimate of IV rt-PA use. ICH identified using ICD-9-CM codes in our 


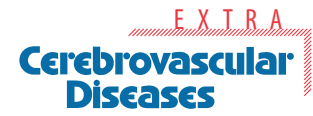

\begin{tabular}{l|l}
\hline Cerebrovasc Dis Extra 2012;2:1-8 \\
\hline $\begin{array}{l}\text { DOI: 10.1159/000335097 } \\
\text { Published online: January 10, } 2012\end{array}$ & $\begin{array}{l}\text { @ 2012 S. Karger AG, Basel } \\
\text { www.karger.com/cee }\end{array}$ \\
\hline
\end{tabular}

study represents all types of ICH (symptomatic and asymptomatic) throughout hospitalization and therefore the rates cannot be compared to studies that provide rates of symptomatic ICH within the first $24-36 \mathrm{~h}$. The differential rate between ICHs in the two patients groups in our study raises the possibility that referring EDs are selecting patients with more favorable characteristics for IV rt-PA compared with EDs of receiving hospitals thus resulting in better outcomes, lower costs, and lower rates of ICH in patients treated by the dripand-ship paradigm.

The results of the drip-and-ship paradigm compare favorably with IV rt-PA treatment through primary ED arrival in this statewide study supporting broader applicability of this strategy.

\section{Acknowledgments/Disclosure Statement}

Dr. Qureshi has received funding from the National Institutes of Health RO1-NS4497601A2 (medication provided by ESP Pharma), American Heart Association Established Investigator Award 0840053N, National Institute of Health U01-NS062091-01A2, and the Minnesota Medical Foundation, Minneapolis, Minn.

\section{References}

1 Tissue plasminogen activator for acute ischemic stroke. The National Institute of Neurological Disorders and Stroke rt-PA Stroke Study Group. N Engl J Med 1995;333:1581-1587.

-2 Rymer MM, Thurtchley D, Summers D: Expanded modes of tissue plasminogen activator delivery in a comprehensive stroke center increases regional acute stroke interventions. Stroke 2003;34:e58e60.

-3 Silverman IE, Beland DK, Chhabra J, McCullough LD: The 'drip-and-ship' approach: starting IV $\mathrm{t}$-PA for acute ischemic stroke at outside hospitals prior to transfer to a regional stroke center. Conn Med 2005;69:613-620.

-4 Martin-Schild S, Morales MM, Khaja AM, Barreto AD, Hallevi H, Abraham A, Sline MR, Jones E, Grotta JC, Savitz SI: Is the drip-and-ship approach to delivering thrombolysis for acute ischemic stroke safe? J Emerg Med 2011;41:135-141.

-5 Pervez MA, Silva G, Masrur S, Betensky RA, Furie KL, Hidalgo R, Lima F, Rosenthal ES, Rost N, Viswanathan A, Schwamm LH: Remote supervision of IV-tPA for acute ischemic stroke by telemedicine or telephone before transfer to a regional stroke center is feasible and safe. Stroke 2010;41:e18e24.

-6 Gregory PM, Rhoads GG, Wilson AC, O'Dowd KJ, Kostis JB: Impact of availability of hospital-based invasive cardiac services on racial differences in the use of these services. Am Heart J 1999;138:507517.

7 Minnesota QuickFacts from the US Census Bureau. http://quickfacts.Census.Gov/qfd/states/27000. html (last accessed on December 17, 2010).

8 The Minnesota Hospital Association. http://www.Mnhospitals.Com/index/abouthosp2 (last accessed on December 17, 2010).

9 National Center for Health Statistics: International Classification of Diseases, Ninth Revision, Clinical Modification. Atlanta, Centers for Disease Control and Prevention, 1980.

-10 Mecozzi AC, Brown DL, Lisabeth LD, Barsan WG, Silbergleit R, Hickenbottom SL, Scott PA, Morgenstern LB: Determining intravenous rt-PA eligibility in the emergency department. Neurocrit Care 2007;7:103-108.

-11 Shuaib A, Khan K, Whittaker T, Amlani S, Crumley P: Introduction of portable computed tomography scanners, in the treatment of acute stroke patients via telemedicine in remote communities. Int J Stroke 2010;5:62-66. 
-12 Meyer BC, Raman R, Hemmen T, Obler R, Zivin JA, Rao R, Thomas RG, Lyden PD: Efficacy of siteindependent telemedicine in the STRoke DOC Trial: a randomised, blinded, prospective study. Lancet Neurol 2008;7:787-795.

-13 Schwamm LH, Pancioli A, Acker JE 3rd, Goldstein LB, Zorowitz RD, Shephard TJ, Moyer P, Gorman M, Johnston SC, Duncan PW, Gorelick P, Frank J, Stranne SK, Smith R, Federspiel W, Horton KB, Magnis E, Adams RJ: Recommendations for the establishment of stroke systems of care: recommendations from the American Stroke Association's Task Force on the Development of Stroke Systems. Stroke 2005;36:690-703.

14 Tonarelli SB, Tibbs M, Vazquez G, Lakshminarayan K, Rodriguez GJ, Qureshi AI: Accuracy of the new ICD-9-CM code for 'drip-and-ship' thrombolytic treatment in patients with ischemic stroke. J Stroke Cerebrovasc Dis 2010, E-pub ahead of print.

-15 Qureshi AI, Harris-Lane P, Siddiqi F, Kirmani JF: International classification of diseases and current procedural terminology codes underestimated thrombolytic use for ischemic stroke. J Clin Epidemiol 2006;59:856-858.

16 International classification of diseases and current procedures. http://www.Cms.Gov/paymentsystems/ icd9/fyadde.Pdf (last accessed on December 17, 2010).

17 Goldstein LB: Accuracy of ICD-9-CM coding for the identification of patients with acute ischemic stroke: effect of modifier codes. Stroke 1998;29:1602-1604.

- 18 Broderick J, Brott T, Kothari R, Miller R, Khoury J, Pancioli A, Gebel J, Mills D, Minneci L, Shukla R: The Greater Cincinnati/Northern Kentucky Stroke Study: preliminary first-ever and total incidence rates of stroke among blacks. Stroke 1998;29:415-421. 